\title{
Development of Some Novel Suction-Based Correlations for Swell Behavior of Expansive Soils
}

\author{
Bakht Zamin $\mathbb{D}^{1},{ }^{1}$ Hassan Nasir, ${ }^{2}$ Khalid Mehmood, ${ }^{3}$ Qaiser Iqbal $\mathbb{D},{ }^{3}$ M. Tariq Bashir, \\ and Asim Farooq ${ }^{4}$ \\ ${ }^{1}$ Civil Engineering Department, CECOS University of IT \& Emerging Sciences, Peshawar, Pakistan \\ ${ }^{2}$ Water and Sanitation Services, Peshawar (WSSP), Peshawar, Pakistan \\ ${ }^{3}$ Civil Engineering Department, Sarhad University of Science \& Information Technology (SUIT), Peshawar, Pakistan \\ ${ }^{4}$ Pak-Austria Fachhochschule: Institute of Applied Sciences \& Technology (PAF-IAST), Haripur, Pakistan
}

Correspondence should be addressed to Bakht Zamin; bakhtzamin82@gmail.com

Received 17 July 2021; Accepted 9 November 2021; Published 30 November 2021

Academic Editor: Giuseppe Di Filippo

Copyright ( 92021 Bakht Zamin et al. This is an open access article distributed under the Creative Commons Attribution License, which permits unrestricted use, distribution, and reproduction in any medium, provided the original work is properly cited.

Swelling and shrinkage are the two distinctive characteristics of expansive soils, and due to this behavior, these soils are considered a natural hazard for infrastructure. Many structures in different regions have been impaired due to the swell/shrink behavior of the expansive soil. Most of the severe distress is impeded because of the inherent suction (negative pore water pressure) present in expansive soils. Both suction and swelling parameters are greatly affected by the surrounding moisture content. Due to this feature of expansive soil, geotechnical engineers are interested in utilizing the suction-based correlations for the assessment of unsaturated expansive soils. The current investigation was carried out to develop novel correlations incorporating lab testing and field instrumentation. To fulfill the objectives, eight sites of the local expansive soil in Pakistan were selected for samples collection and field testing. Conventional odometer testing was conducted to measure the swell pressure $\left(S_{p}\right)$ and swell potential $(S)$ of the fabricated/remolded specimens. Gypsum block (G-block) sensors were additionally utilized for estimating the matric suction in the field. To expand the database, the previously published data of the same nature was also incorporated. Based on the results, the power form of the novel correlations (suction-based) is highly significant for estimating $\left(S_{p}\right)$, while for swell potential, the logarithmic correlation with $R^{2}=0.6551$ is more significant than other forms of correlations. The proposed suction-based correlation can be equally utilized for the estimation of field suction as well as for swell behavior of expansive soil having a plasticity index $(\mathrm{PI}) \geq 22 \%$.

\section{Introduction}

Expansive soil is a specific type of soil in which large-volume changes take place due to fluctuations in its moisture content. The volume changes occur in two different ways, namely, expansion and contraction or shrinkage. The expansion will occur when such soil is inundated in water due to absorption, while shrinkage happens when its moisture is extracted or evaporated. Expansion is triggered from the dry or partially saturated condition and continues until full absorption. Expansive soils are highly sensitive to moisture, due to which detrimental expansion and contraction can occur upon the minute increase in the water content. It is worth mentioning that such soils exert swell pressure in confined conditions, and lightweight structures may lift or heave up. Conversely, in dry conditions, these structures settle down differentially due to shrinkage phenomena.

Expansive soils are assumed to be challenging for soil engineers; notwithstanding, the majority of the basic issues are minimized because of the suction (negative pore water pressure) presence in such soils. Recent research has recommended that the expansive behavior of soils could be assessed in a better way if the matric suction is considered in the investigations. The matric suction relies upon measurement of water content and chemical and physical characteristic of soils, including specific surface area, 
mineralogical composition, stress condition, structure, relative compaction, voids ratio, and pore size distribution, in which the moisture content is more significant among different elements while dealing with the swell and shrinkage parameters. Most recent investigations reported that suction is independent of soil mineralogy; however, it exceptionally relies upon the arrangement of the pore moisture saturating the soil [1]. The measurement of suction not only involved extensive instrumentation but was also time-consuming. Hence, it is better to approximate the matric suction from suction-based correlations.

The currently utilized practice correlates swell-shrink characteristics of the soil to the index properties and mineralogical compositions and is based on the lab results alone. This methodology restricts the real governing parameters and specific field conditions which are involved in the assessment of expansive soils. For exactness and precision, there is a need to correlate the swell parameters of the swelling soil with the soil suction estimated in the field circumstances.

The present investigation was conducted to assess the fundamental engineering and swelling characteristics of local expansive soils and to develop novel suction-based correlations for swell pressure $\left(S_{p}\right)$ and swell potential $(S)$. The advancement of new relationships between matric suction and swell parameters can be utilized subsequently by practicing engineers when dealing with such sorts of problematic soils. Additionally, these correlations can be used for measuring swell conduct from suction and vice versa. The proposed findings can be incorporated in the design protocol of shallow foundations to protect them from major damage caused by expansive soils.

\section{Failure Mechanism of Structures}

The adversity of expansive soils is more critical to lightly loaded structures due to the swell pressure. The mechanism of swell pressure is a very complicated and complex behavior and often uplifts the structure, resulting in minor distress or major destruction [2-4]. The volume of swelling soils increases equally in all directions upon the moisture absorption from the surrounding. However, in the field, where structures are built on foundation soils, then expansion in volume occurs in a vertically upward direction only, and lateral swell is resisted by the confining soils. Due to this phenomenon, structures will lift up or settle down only in a humid environment and cyclic dry period, respectively.

The major causes of moisture fluctuations are rainfall, leakage from water supply lines or drains, changes to drainage of the surface, and landscaping, including paving. In severe dry conditions, practically it is not possible to supply water to desiccated soil as efficiently as a tree primitively extracted from the soil through its root system [6]. It is worth mentioning that the variation in water content of the swell/shrink soil can affect the structures in two distinct ways, that is, end lift failure and center lift failure, as mentioned in Figure 1. In the end lift mechanism, expansion occurs in the perimeter of the structure and remains unchanged at the center, while in the center, lift
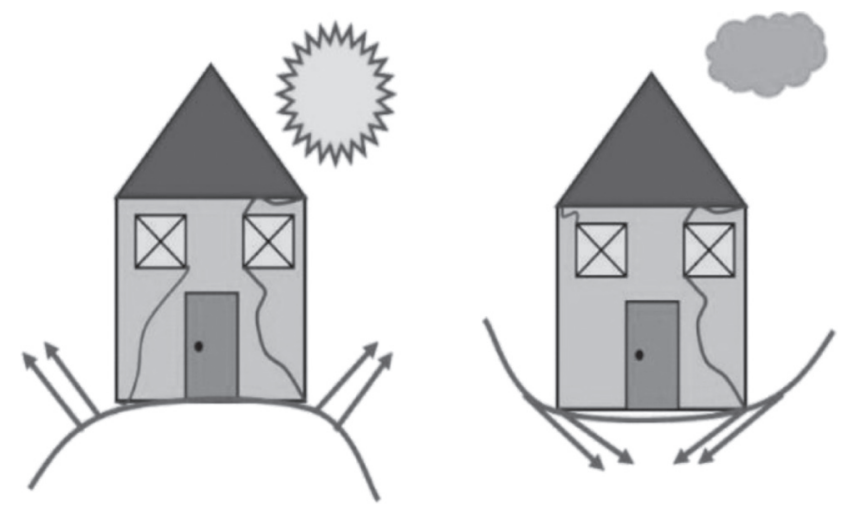

FIGURE 1: Swell and shrinkage in the perimeter of a structure during cyclic wet and dry conditions [5].

mechanism shrinkage occurs in the perimeter of the structure [7].

Shallow foundations are often damaged by the shrinkage advanced by vegetation. This shrinkage happens when the vegetation degrades the water profile in the vadose zone. Vegetation elevated changes to water profiles can importantly affect other underground constructions and utility services. Additionally, expansive soils exert swell pressure (stress) on the vertical faces of the foundations and retaining walls resulting in lateral deflection. Besides, a decrease in the shear strength of foundation soils and reduction in ultimate capacity could result in loss of shear strength of soil or instability in bearing capacity [8]. Various investigators have highlighted the problems associated with swelling soils; for example, the transportation system has deteriorated by the repeated swelling and shrinkage of Regina expansive soil [9]. Different types of foundations, roads, and other facilities are susceptible to distress because of the presence of expansive soils [10,11]. The distress is more critical when differential settlements occur due to shrinkage, and their maintenance cost is increased.

\section{Background Study}

Matric suction is one of the best indicators of swell potential, and few investigations have been successfully conducted for estimating the swelling capacity of expansive soils from matric suction. Numerous research studies [12, 13] have investigated the hydromechanical properties of expansive soil for evaluating the swell stress, soil suction, and other related properties. The latest studies reported that the physical arrangement of particles inside the soil specimen is controlled by the matric suction, which can contribute to the volume variations [14-16].

Various investigations assumed that matric attractions are associated with the swell pressure of expansive soil [17-20]. Swelling soil can be assessed in a better way from suction measurements because most of the time it remains in the unsaturated condition in the field. Despite the availability of numerous literature in this domain, further refinement is needed for practical applications. 
The matric suction and swelling are the two major features of expansive soils and are based fundamentally upon the physical, mineralogical, and environmental characteristics of the soils. Various analysts have conducted extensive investigations in the past couple of years for presenting useful information for designing, planning, and analyzing preventive measures to evaluate the potential issues related to volume change in swelling soil. To the author's best knowledge, most of the previous investigations are based on lab testing, and little attention has been given to field instrumentation. It is, therefore, desirable to conduct research investigation overutilizing a novel and more accurate methodology in which soil matric potential is the key variable for estimating the swell behavior of expansive soil. The swell behavior in terms of swell potential and swell pressure with change in water content due to environmental changes is specifically studied by [21]. Pandya and Sachan, 2018, have assessed the swelling and matric suction of four high expansive soils with different mineralogical compositions [22]. The examination revealed that irrespective of the degree of saturation, matric suction would be high for soil with a higher free swell index value. Basma et al., 1995; Komine and Ogata $[12,15]$ analyzed the hydromechanical properties of heaving soil by assessing the swell pressure, matric suction, and other concerning parameters. Kandemir et al. [23] determined the swell pressure from the matric potential of expansive soils. It was found that a straight relationship exists between logarithmic matric potential and swell pressure. According to Lin and Cerato, Erol and Ergun, and Erzin and Erol investigation, a strong relationship existed between the matric potential and swelling pressure, and expansive soils with high matric suction had high swell pressure [24-26].

\section{Samples Collection and Field Testing}

For material characterization, detailed experimental work was carried out in the lab as well as in the field. The basic material in this study was the expansive soil collected from eight different locations of Khyber Pakhtunkhwa (KPK), Pakistan, that is, three sites in Karak, three sites in Kohat, and two sites in D.I Khan Areas. Field testing was also conducted in these sites. The coordinates of these sites are as follows:

Karak: $33^{\circ} 33^{\prime} 10.8^{\prime \prime} \mathrm{N} 71^{\circ} 25^{\prime} 44.4^{\prime \prime} \mathrm{E}$, Kohat: $33^{\circ} 05^{\prime} 39.8^{\prime \prime} \mathrm{N}$ $71^{\circ} 04^{\prime} 42.6^{\prime \prime} \mathrm{E}$, and D.I Khan: $31^{\circ} 53^{\prime} 49^{\prime \prime} \mathrm{N} 70^{\circ} 47^{\prime} 34^{\prime \prime} \mathrm{E}$ [27].

To expand the database for correlations development, eight independent locations for random sampling were considered in this experimental study. Physically disturbed specimens were collected from open test trenches. The collected samples were assessed for their fundamental geotechnical properties and swelling behavior according to the ASTM testing methodology. Field testing was additionally performed by installing G-block (Gypsum block) sensors and tensiometers in the same test trenches, as evident from Figure 2.
4.1. Initial Testing and Classification. The lab testing was conducted in evaluating the essential geotechnical and swelling properties as mentioned in the following:

(i) The flow parameters, including liquid limit (LL), plastic limit (PL), and plasticity index (PI) of the collected samples, were determined according to the ASTM D-4318 test procedure

(ii) The gradation of expansive soil was evaluated by mechanical sieve analysis following the ASTM D-422

(iii) The swelling characteristics in terms of swell pressure $\left(S_{p}\right)$ and swell potential $(S)$ were investigated by conducting the conventional oedometer test according to the ASTM D-4546-03 testing methodology

(iv) For assessing the optimum moisture content (OMC) and maximum dry density (MDD), the proctor compaction tests standardized under ASTM D-698-A were conducted

(v) The matric suction in the field was measured with the help of tensiometers and G-block sensors according to the given manual

(vi) For classification purposes, both the unified soil classification system (USCS) and Chen criteria were incorporated

\section{Experimental Results}

The initial geotechnical properties of the eight investigated expansive soils are listed in Table 1.

Based on the liquid limits (LL) and plasticity index (PI) values, the respective positions of the investigated expansive soils have been marked on the plasticity chart as shown in Figure 3.

The plot showed all the selected soils that were set over A-line, being inorganic with high and low plasticity. Based on the plasticity index, these soils have been classified according to USCS and Chen criteria. The details are presented in Table 2. It is well clear from the classification table that most of the selected soil fulfills the high and medium expansive soils criteria as given in Table 2 .

The swell potential $(S)$ and swell pressure $\left(S_{p}\right)$ of the entire eight sites were determined from samples fabricated at OMC as described in Figure 4. The obtained results are summarized and appear in Table 3.

The outcomes of the results showed that the sample " $S_{1}$ " from the Karak site has the highest values of swelling, while the sample $S_{5}$ from the D.I Khan area presented the minimum value of the swell characteristic. The contrast between examples $S_{4}$ and $S_{5}$ was not recognizable because these soils were collected from locations with similar land and ecological conditions. The Kohat soil acquired an intermediate position between the Karak and D.I Khan's soil, although a sample from Kohat $\left(S_{8}\right)$ showed some identical results as that of Karak's soil. 


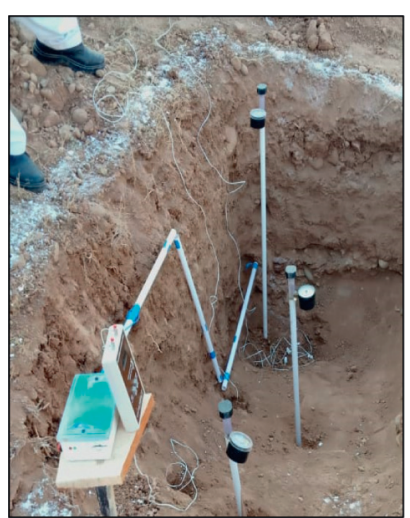

(a)

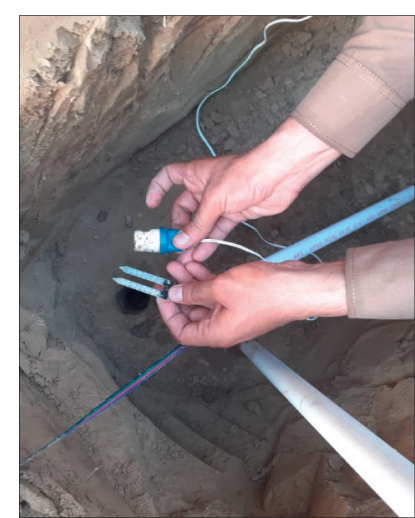

(b)

FIGURE 2: The installation process of G-block and moisture sensors [28].

TABLE 1: Initial geotechnical and compaction properties of the investigated soils.

\begin{tabular}{lccccc}
\hline Locations & Designation & LL (\%) & PL (\%) & PI (\%) & $\begin{array}{c}\gamma d \max \\
\left(\mathrm{kN} / \mathrm{m}^{3}\right)\end{array}$ \\
\hline \multirow{3}{*}{ Karak } & $S_{1}$ & 60 & 23 & 37 & 17.4 \\
& $S_{2}$ & 55 & 21 & 34 & 17.8 \\
\multirow{2}{*}{ D.I Khan } & $S_{3}$ & 52 & 18 & 34 & 18.5 \\
\hline \multirow{3}{*}{ Kohat } & $S_{4}$ & 34 & 11 & 23 & 16.9 \\
& $S_{5}$ & 33 & 11 & 22 & 17.6 \\
\hline & $S_{6}$ & 48 & 19 & 27 & 18.8 \\
& $S_{7}$ & 46 & 21 & 25 & 18.3 \\
& $S_{8}$ & 50.5 & 20 & 30.5 & 17.4 \\
\hline
\end{tabular}

\section{Suction-Based Correlations for Swell Pressure}

The developed relationships between swell pressure and matric suction measured at OMC in the field for the explored soils are illustrated. The different formats of relationships were used to track down the best fitting curve for the data obtained from field and lab testing. The various formats incorporated in correlations advancement are linear, logarithmic, power, exponential, and polynomial. The proposed relationships were also strengthened by the most reliable data from the investigation carried out by Thompson et al. and Singhal et al. [30, 31]. For expanding the database, the most relevant data were added, which were based on the plasticity index (PI) value and testing condition. The minimum limit of PI was kept $\geq 22$ with the goal that a wide range of swelling soils can be covered in these novel relationship models.

The linear relationship between swell pressure and matric suction is introduced in Figure 5.

Based on the results of the current investigation and recently published research of similar nature, a strong straight correlation exists between the swell pressure and field matric suction. This correlation is highly significant with an $R^{2}=0.8162$. This shows that about $82 \%$ percent of changes will occur in this relationship because of the changes in suction and swell pressure. Other variables are contributing to only $18 \%$ in this novel correlation.
The novel correlation (exponential) for swell pressure and field matric suction has been presented in Figure 6 . $R^{2}=0.7529$ shows that the accuracy of this relationship is less than the linear correlation.

The newly developed suction-based logarithmic and polynomial correlations for swell pressure have been presented in Figures 7 and 8 . The regression $R^{2}$ value is equal to 0.7575 and 0.821 , respectively. Based on the $R^{2}$ values, the polynomial correlation can be used for more accurate estimation.

Figure 9 presents the novel suction-based correlation (power form) for swell pressure. It was found that $R^{2}$ is the highest and equal to 0.8446 . From these developed correlations, it is clear that the power correlation is more significant than other relationships, while the exponential correlation has the least significance level.

6.1. Validation of Novel Suction-Based Correlation. The novel suction-based correlations for swell pressure $\left(S_{p}\right)$ and field matric suction have been summarized and presented in Table 4 along with their significance level.

The summary showed that, in newly developed suctionbased correlations, the power form is more significant than other correlations. To validate the novel correlations, independent practical data of Hollywood, Heiden, and Eagle Ford expansive soils [24] were taken. The cumulative error was determined for these expansive soils. The cumulative error was then compared with the error found in Janardhan et al. correlation [32]. The regression model (equation) with the least $R^{2}$ value from the current study was incorporated for comparison and validation purposes. The independent data of expansive soils utilized in this validation are referenced in Table 5, while the selected regression models are also summarized in Table 6.

The proposed novel correlations were compared with the Janardhan et al. regression equations for checking the validity of these correlations. The independent data of the medium, high, and very high expansive soils was incorporated as presented in Figure 10. It was found that novel correlations showed comparable results with the previous correlations for medium and high expansive soil. However, 


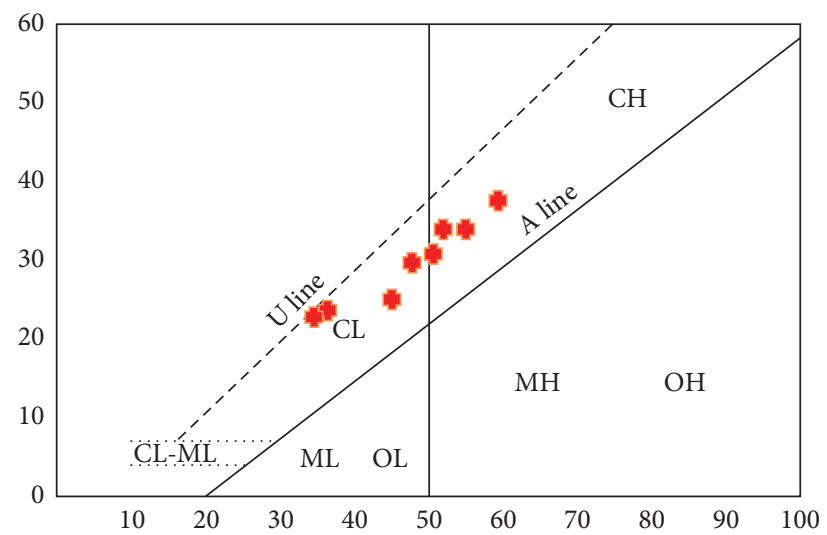

Figure 3: Position of the investigated soil on Casagrande plasticity chart.

TABLe 2: Classification of the investigated soil concerning USCS and Chen criteria [29].

\begin{tabular}{lcccc}
\hline Designation & $\begin{array}{c}\text { PI } \\
(\%)\end{array}$ & USCSclassification & Expansivity & $\begin{array}{c}\text { Chen } \\
\text { criteria }\end{array}$ \\
\hline$S_{1}$ & 37 & $\mathrm{CH}$ & High & PI $=10-15$ \\
Low & & & High & \\
$S_{2}$ & 34 & $\mathrm{CH}$ & High & PI $=15-28$ \\
$S_{3}$ & 34 & $\mathrm{CH}$ & Medium & \\
Medium & & & Medium & PI $=28-41$ \\
$S_{4}$ & 23 & $\mathrm{CL}$ & Medium & \\
$S_{5}$ & 22 & $\mathrm{CL}$ & & \\
High & & & Medium & $>41$ \\
$S_{6}$ & 27 & $\mathrm{CL}$ & High & \\
$S_{7}$ & 25 & $\mathrm{CL}$ & & \\
Very high & & $\mathrm{CH}$ & & \\
$S_{8}$ & 30.5 & & & \\
\hline
\end{tabular}

in the case of extremely high expansive soil, the current model is more stable than the Janardhan model for predicting the swell pressure from field matric suction as mentioned in Table 7.

\section{Suction-Based Correlations for Swell Potential}

The created relationships between swell potential $(S)$ and matric attractions $\left(\Psi_{\text {omc }}\right)$ for the tested soils are mentioned in Figures 11-15. The different available formats of equations were used to find the best fitting correlations curves. The most suitable data previously investigated by Lin and Cerato, Puppala et al., and Janardhan et al. [24, 32, 33] were additionally incorporated to expand the database. The plasticity index and test conditions were the two major factors considered in the selection of previous data. To cover a wide range of expansive soils, the plasticity index was considered to be $\geq 22 \%$.

In light of the consequences of the current investigation and recently published literature of a similar domain, it is found that high and medium significance level correlations can be developed. The significance level of these correlations depends on the nature of the equations. It is clear from Figure 13 that logarithmic correlation is more significant due to the high value of $R^{2}=0.6551$. In this correlation, about $66 \%$ of variations will occur due to changes in swell potential and matric suction. It is additionally certain that different other factors contribute about $34 \%$ to this novel relationship.

The novel linear and exponential correlations based on field suction for swell potential are presented in Figures 11 and 12 with $R^{2}$ equal to 0.649 and 0.5772 , respectively. These correlations are also appearing as equations (1) and (2), respectively:

$$
\begin{aligned}
& S=0.0092 \psi_{\mathrm{omc}}+0.4275 \\
& S=2.3316 e^{0.0018 \times \psi_{\mathrm{omc}}}
\end{aligned}
$$

The other formats of correlations like the logarithmic and the polynomial swell potential predication are also described in Figures 13 and 14 with $R^{2}$ equal to 0.6551 and 0.6491 , respectively.

Figure 15 represents the power correlation between the swell potential and matric suction with $R^{2}=0.6184$. The correlation is moderately significant having a $62 \%$ contribution of the selected variables.

7.1. Validation of Novel Correlations for Swell Potential. The newly created relationships for swell potential $(S)$ and matric potential $\left(\Psi_{\text {omc }}\right)$ have been combined up and presented in Table 8 . The logarithmic form of the new correlation connection has the most elevated importance level, while the exponential relationship has moderate significance. Because of the current results and previously investigated data in the same domain, all the newly developed correlations can be used for measuring the approximate value of swell potential from the field suction.

For validation purposes, independent data previously published for Hollywood, Heiden, and Eagle Ford expansive soil were incorporated, and the cumulative error was calculated from the actual values. The results of cumulative error were then compared with the Janardhan et al. correlation equations. The models with minimum $R^{2}$ value were utilized for comparison purposes. The determinations of the independent soil are referenced in Table 9, and the outline of the assumed model regression models is also introduced in Table 10 . 


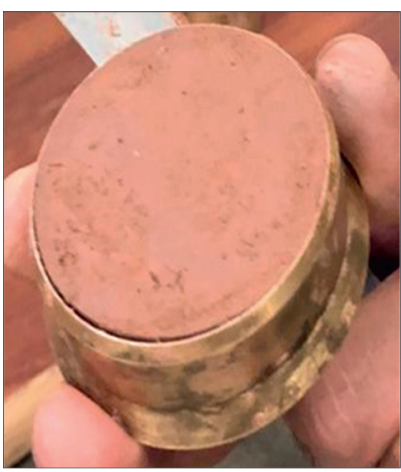

(a)

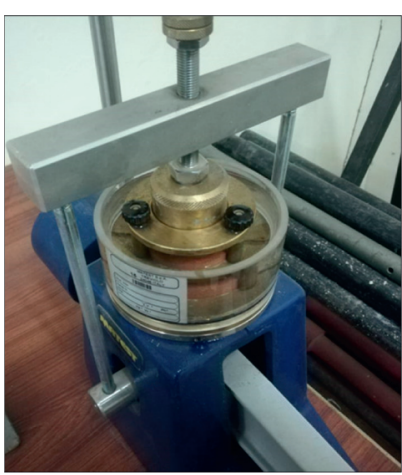

(b)

FIGURE 4: Fabrication of specimen for swell pressure and oedometer used in this study.

TABLE 3: Summary of swell potential $(S)$ and swell pressure $\left(S_{p}\right)$ of the investigated expansive soils.

\begin{tabular}{lccc}
\hline Locations & Samples designation & Swell potential (\%) & Swell pressure (kPa) \\
\hline \multirow{3}{*}{ Karak } & $S_{1}$ & 9.6 & 275 \\
& $S_{2}$ & 7.8 & 240 \\
\hline \multirow{2}{*}{ D.I Khan } & $S_{3}$ & 5.4 & 152 \\
\hline \multirow{2}{*}{ Kohat } & $S_{4}$ & 6.9 & 195 \\
& $S_{5}$ & 6.5 & 182 \\
\hline
\end{tabular}

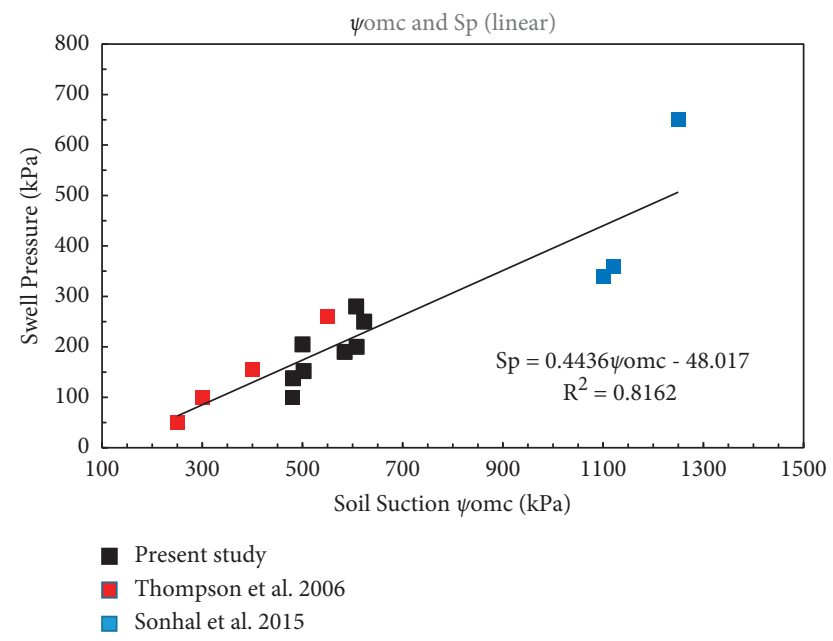

FIGURE 5: Presentation of novel suction-based linear correlation for swell pressure.

The cumulative errors that occurred in the current and previous regression models are presented in Figure 16. The comparison showed that the calculated error in the current model is less than the previous models for all the three formats (medium, high, and very high) expansive soils. Based on the comparison results, it was noted that the current models are more stable than the previously presented models. The details of the error that occurred for the three types of expansive soils are demonstrated in Table 11. 


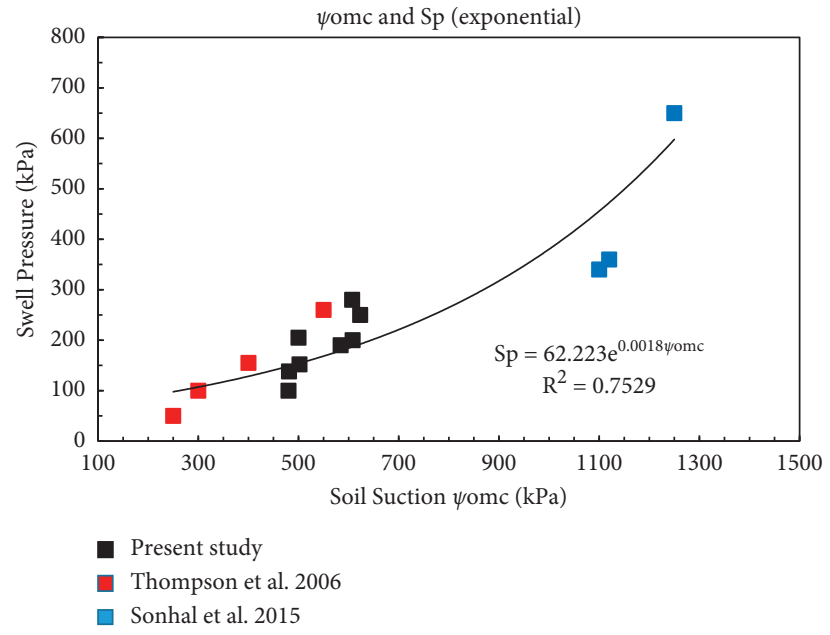

Figure 6: Presentation of suction-based exponential relation for swell pressure.

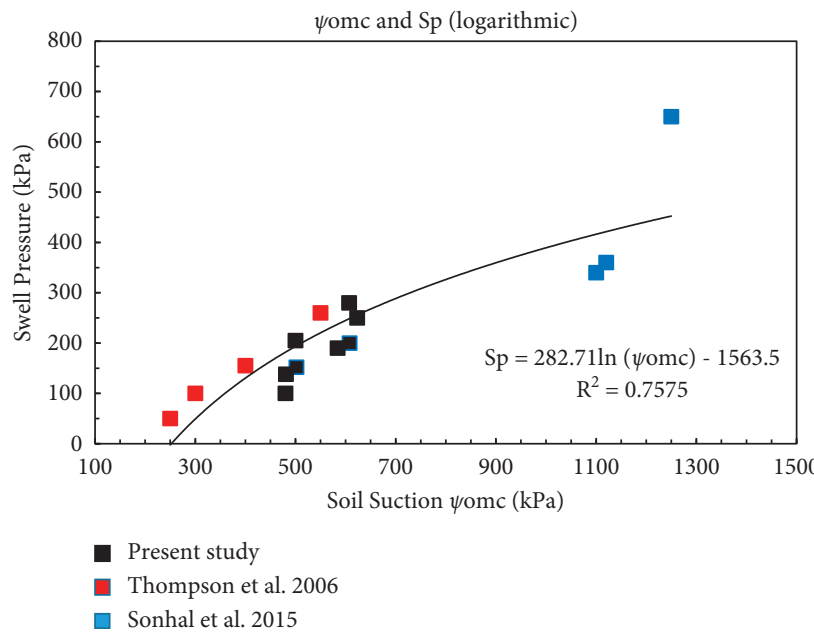

FIgURE 7: Presentation of suction-based logarithmic correlation for swell pressure.

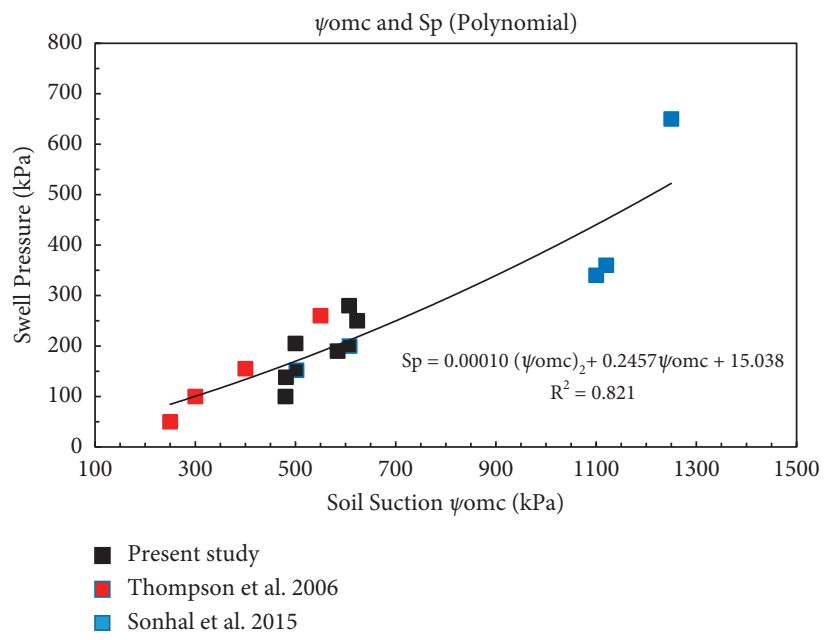

FIGURE 8: Presentation of suction-based polynomial correlation for swell pressure. 


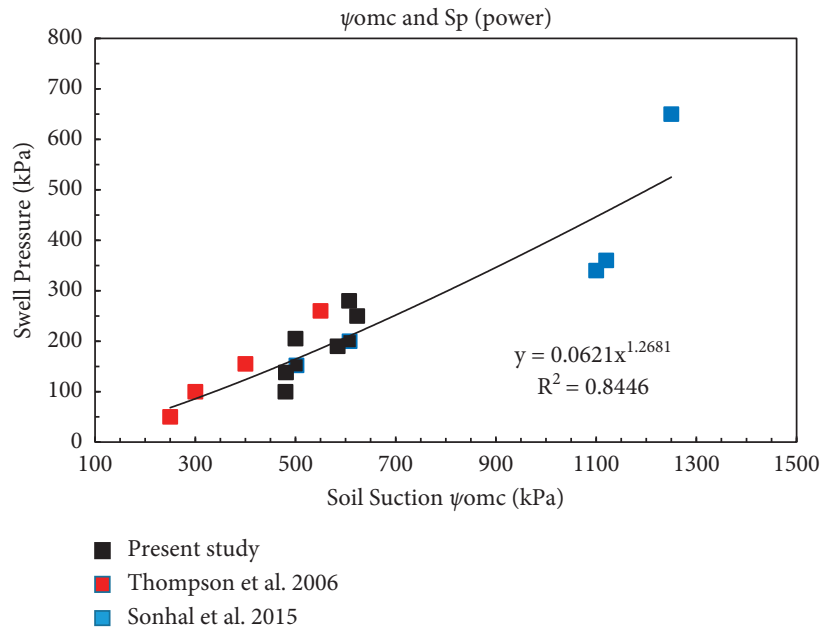

Figure 9: The newly developed suction-based correlation for swell pressure.

TABLE 4: The summary of the newly proposed suction-based correlations with their respective $R^{2}$ values.

\begin{tabular}{lccc}
\hline Correlations & Equations & $R^{2}$ & Significance \\
\hline Linear & $S_{p}=0.4436 \psi_{\text {omc }}-48.017$ & 0.8162 & High \\
Exponential & $S_{p}=62.223 e^{0.0018 \times \psi_{\text {omc }}}$ & 0.7529 & Moderate \\
Logarithmic & $S_{p}=282.71 \ln \psi_{\text {omc }}-1563.5$ & 0.7575 & Moderate \\
Polynomial & $S_{p}=0.0001\left(\psi_{\text {omc }}\right)^{2}+0.2457 \psi_{\text {omc }}+15.031$ & 0.821 & High \\
Power & $S_{p}=0.0621\left(\psi_{\text {omc }}\right)^{1.2681}$ & 0.8446 & High \\
\hline
\end{tabular}

TABLE 5: Specification of the independent expansive soils utilized for validation.

\begin{tabular}{|c|c|c|c|c|c|}
\hline Serial no. & Tested soils & Expansiveness & PI (\%) & $S_{p}$ & $\Psi_{\text {omc }}$ \\
\hline 1 & Hollywood & Medium & 34 & 141 & 565 \\
\hline 2 & Heiden & High & 48 & 230 & 771 \\
\hline 3 & Eagle Ford & Very high & 57 & 263 & 1040 \\
\hline
\end{tabular}

TABLE 6: Selected regression equations considered for validation purpose.

\begin{tabular}{lcc}
\hline Correlations & Equations & $R^{2}$ \\
\hline Current study & $S_{p}=62.223 e^{0.0018 \psi_{\text {omc }}}$ & 0.7529 \\
Janardhan et al. & $\log \left(S_{p}\right)=2.25 \times \log \left(\psi_{\text {omc }}\right)-5.1199$ & 0.680 \\
\hline
\end{tabular}

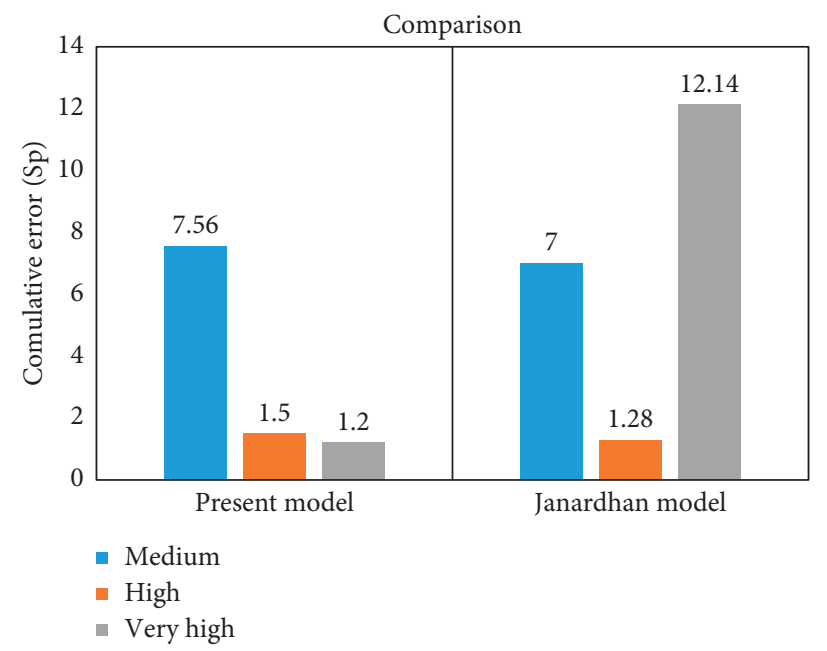

FIgURE 10: Comparison of the cumulative errors that occurred in the two models. 
TABLE 7: Summary of the cumulative error found in the suction-based correlation for swell pressure.

\begin{tabular}{lccc}
\hline Tested soils & Expansiveness & Error Janardhan model & Error present model \\
\hline Hollywood & Medium & 7.0 & 7.56 \\
Heiden & High & 1.28 & 1.5 \\
Eagle Ford & Very high & 12.14 & 1.2 \\
\hline
\end{tabular}

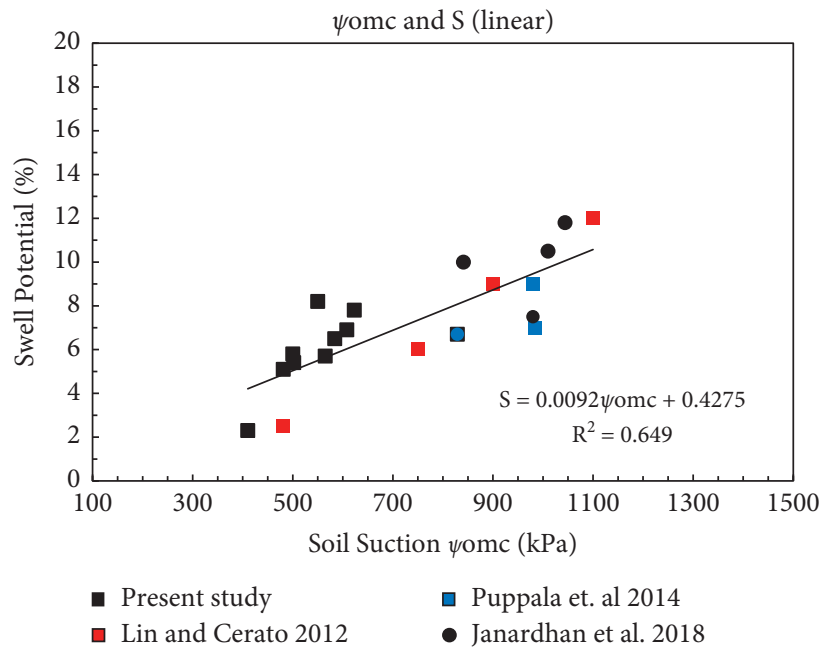

FIGURE 11: Linear correlation between swell potential and matric suction.

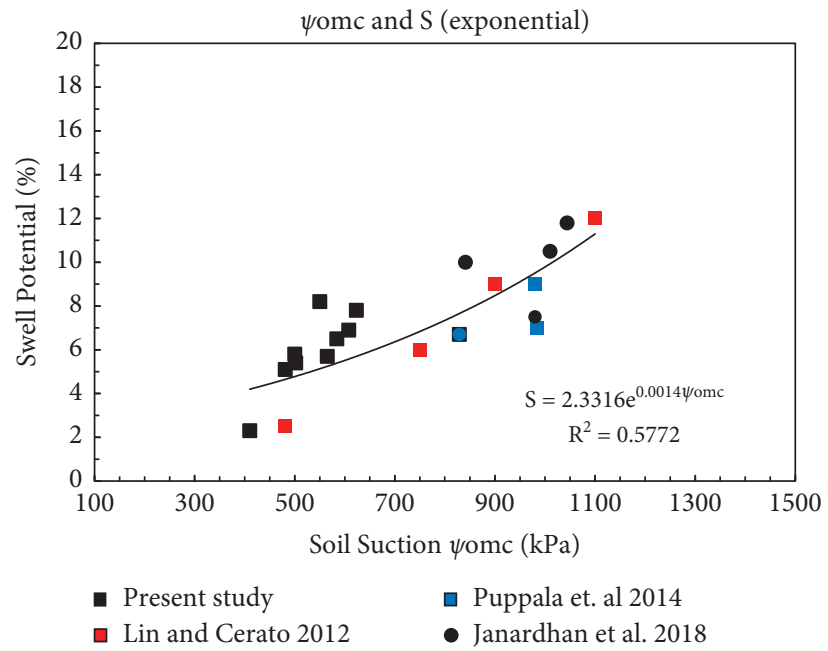

FigURE 12: The exponential correlation between swell potential and matric suction. 


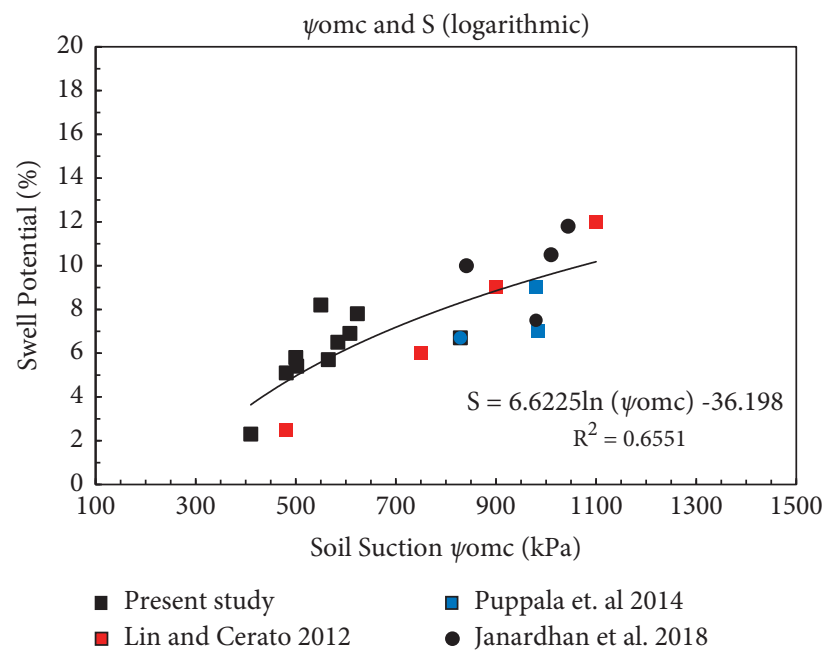

FIGURE 13: Demonstration of the logarithmic suction-based correlation for swell potential.

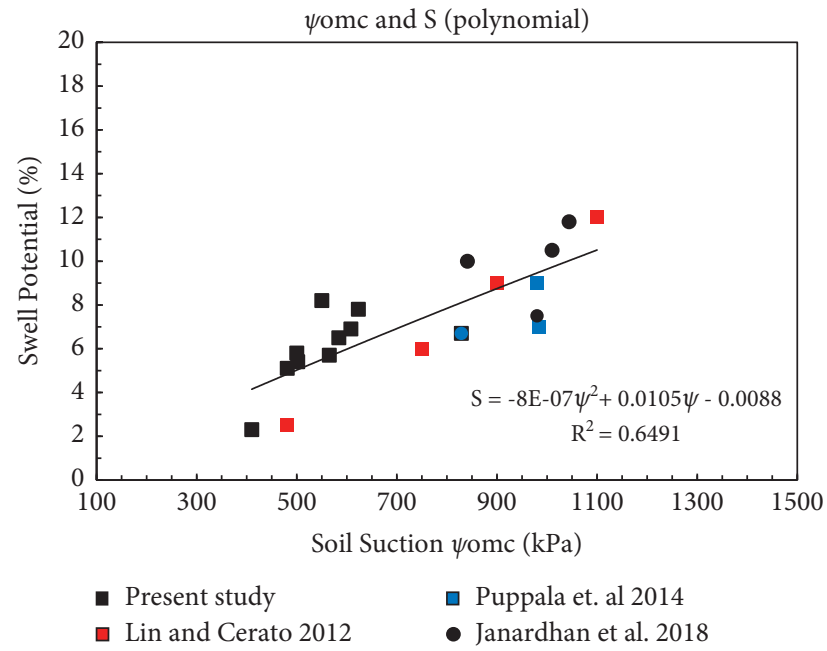

FIGURE 14: Demonstration of the newly developed polynomial correlation for the swell potential of swelling soils.

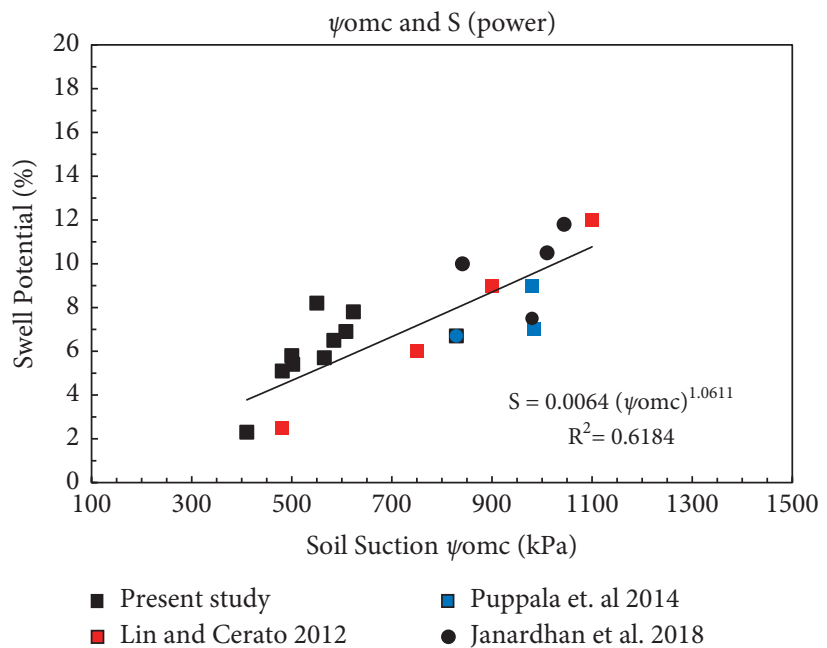

FIgURE 15: Representation of the novel correlation (power) for the swell potential estimation. 
TABLE 8: Summary of suction-based correlations for swell potential along with $R^{2}$ values.

\begin{tabular}{lccc}
\hline Correlations & Equations & $R^{2}$ & Significance \\
\hline Linear & $S=0.0092 \psi_{\mathrm{omc}}+0.4275$ & 0.649 & High \\
Exponential & $S=2.3316 e^{0.0018 \times \psi_{\mathrm{omc}}}$ & 0.5772 & Moderate \\
Logarithmic & $S=6.6225 \ln \psi_{\mathrm{omc}}-36.198$ & 0.6551 & High \\
Polynomial & $S=-8 E-07\left(\psi_{\mathrm{omc}}\right)^{2}-0.0105 \psi_{\mathrm{omc}}-0.0088$ & 0.6491 & High \\
Power & $S=0.064\left(\psi_{\mathrm{omc}}\right)^{1.0611}$ & 0.6184 & High \\
\hline
\end{tabular}

Table 9: Specification of independent test soils incorporated for validation of swell potential models.

\begin{tabular}{|c|c|c|c|c|c|}
\hline Serial no. & Tested soils & Expansiveness & PI (\%) & $\Psi_{\mathrm{omc}}$ & $S$ \\
\hline 1 & Hollywood & Medium & 34 & 565 & 2.3 \\
\hline 2 & Heiden & High & 48 & 771 & 9.3 \\
\hline 3 & Eagle Ford & Very high & 57 & 1040 & 12.7 \\
\hline
\end{tabular}

TABLE 10: The regression equation (models) considered in the validation process.

\begin{tabular}{lcc}
\hline Correlations & Equations & $R^{2}$ \\
\hline Current study & $S=2.3316 e^{0.0018 \times \psi_{\text {omc }}}$ & 0.5772 \\
Janardhan et al. & $S=-3.628+1.5 \times \log \left(\psi_{\text {omc }}\right)$ & 0.69 \\
\hline
\end{tabular}

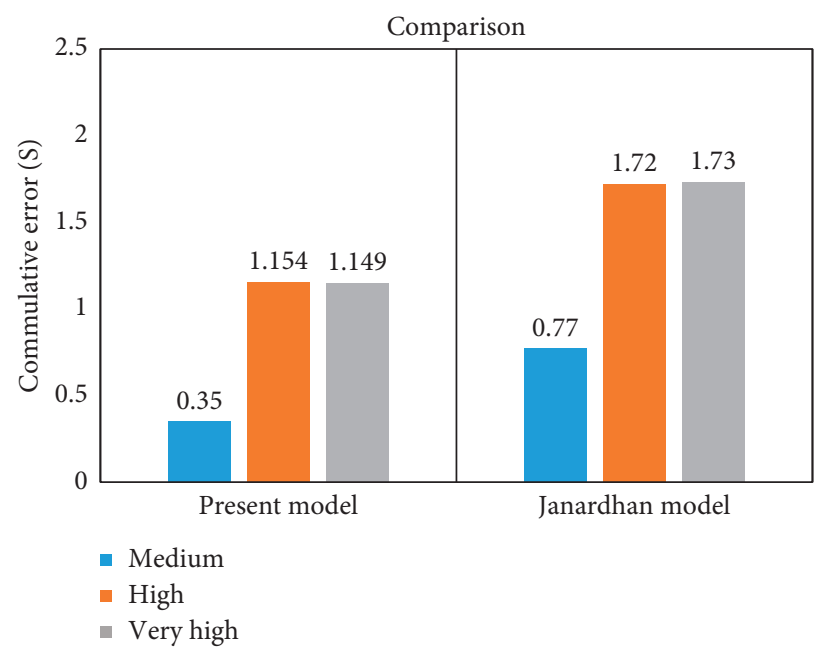

FIGURE 16: Comparison of cumulative errors in the current and previous models.

TABLE 11: Demonstration of the cumulative errors that occurred for the three types of expansive soils.

\begin{tabular}{lccc}
\hline Tested soils & Expansiveness & Error Janardhan model & Error present model \\
\hline Hollywood & Medium & 0.77 & 0.35 \\
Heiden & High & 1.72 & 1.154 \\
Eagle Ford & Very high & 1.73 & 1.149 \\
\hline
\end{tabular}




\section{Conclusions and Recommendations}

8.1. Conclusions. The current investigation comprised of field instrumentation and lab testing was conducted for developing some novel suction-based correlations for estimating swell parameters of local expansive soils. The major conclusions drawn from this experimental study are listed in the following section:

(1) Basic geotechnical characteristics and designation of the eight local expansive soils investigated in the current study evaluated that Karak's soil is more critical in wet conditions than Kohat and D.I Khan's expansive soil for the construction of lightweight structures.

(2) Due to the high liquid limit and plasticity index, Karak's soil has more swelling potential and swell pressure than the other two regions.

(3) Karak's soil showed the maximum value of field matric suction, while D. I Khan's expansive soil has the least matric suction.

(4) From the advancement of correlations, it is concluded that the power format of the suction-based relationship is highly significant for measuring the swell pressure of expansive soils.

(5) The logarithmic correlations are more significant in the newly developed regression equation for estimating the swell potential from field-measured suction.

(6) As matric suction increases, the swell pressure and swell potential also increase for expansive soils. This shows that high expansive are more stable in dry conditions due to the presence of matric suction.

(7) More precision in the design protocol can be achieved if suction-based correlations are utilized for determining the swell pressure and swell potential of the expansive soils.

(8) For the development of regression models/equations, it is necessary to increase the database by adding more and more data either by increasing the number of tests or by incorporating the previous data.

(9) It is additionally closed from the outcomes that most logical information could be gained from the sensors introduced at the center of the open trenches (vadose zone) as it is least affected by the climate and surrounding soil. Besides, minimal aggravation to the local soil during the sensor insertion would give more accurate data for investigations.

\subsection{Recommendations.}

(1) The matric suction is one of the major concerns in the framework of unsaturated soil mechanics. It is recommended to utilize the presented novel correlations for a better assessment of expansive soil behavior.
(2) The swelling and shrinkage are the two main characteristics of the expansive soil. In the current investigation, only the swell behavior in terms of swell pressure and swell potential was considered; further research is recommended in which the shrinkage is considered as a major concern.

(3) Further investigation is also required in the same domain for expanding the database of suction-based correlations of expansive soil for swell behavior.

(4) There is also a research gap present in the available literature where some advancement is required for correlations to be developed based on the suction values measured in the lab.

(5) The proposed suction-based correlation can equally be utilized for the estimation of field suction as well as for swell behavior. However, better results can be achieved if the plasticity index is within the mentioned range.

\section{Data Availability}

The background data utilized during this research work are available to support this study and can be acquired from the corresponding author upon demand.

\section{Conflicts of Interest}

The authors declare that they have no conflicts of interest.

\section{References}

[1] C. W. W. Ng, L. T. Zhan, C. G. Bao, D. G. Fredlund, and B. W. Gong, "Performance of an unsaturated expansive soil slope subjected to artificial rainfall infiltration," Géotechnique, vol. 53, no. 2, pp. 143-157, 2003.

[2] P. T. Bobrowsky and B. Marker, Encyclopedia of Engineering Geology, Springer, Cham, Switzerland, 2018.

[3] F. G. Bell and M. G. Culshaw, "Problems soils: a review from a British perspective," in Problematic Soils: Proceedings of the Symposium Held at the Nottingham Trent University on 8 November 2001, pp. 1-35, Thomas Telford Publishing, London, UK, 2001.

[4] R. D. Holtz, W. D. Kovacs, and T. C. Sheahan, An Introduction to Geotechnical Engineering, Vol. 733, Prentice-Hall, , Englewood Cliffs, NJ, USA, 1981.

[5] E. Chibowski, "Flocculation and dispersion phenomena in soils," in Encyclopedia of Agrophysics, pp. 301-304, Springer, Dordrecht, Netherlands, 2011.

[6] B. Kalantari, "Foundations on expansive soils: a Review," Research Journal of Applied Sciences, Engineering, and Technology, vol. 4, no. 18, pp. 3231-3237, 2012.

[7] M. M. Zumrawi, "Construction problems of light structures founded on expansive soils in Sudan," International Journal of Science and Research, vol. 4, no. 8, pp. 896-902, 2015.

[8] A. Al-Swaidani, I. Hammoud, and A. Meziab, "Effect of adding natural pozzolana on geotechnical properties of limestabilized clayey soil," Journal of Rock Mechanics and Geotechnical Engineering, vol. 8, no. 5, pp. 714-725, 2016.

[9] M. Mokhtari and M. Dehghani, "Swell-shrink behavior of expansive soils, damage, and control," Electronic Journal of Geotechnical Engineering, vol. 17, pp. 2673-2682, 2012. 
[10] F. Khademi and J. Budiman, "Expansive soil: causes and treatments," I-Manager's Journal on Civil Engineering, vol. 6, no. 3, p. 1, 2016.

[11] C. R. I. Clayton, M. Xu, J. T. Whiter, A. Ham, and M. Rust, "Stresses in cast-iron pipes due to seasonal shrink-swell of clay soils," Proceedings of the Institution of Civil Engineers - Water Management, vol. 163, no. 3, pp. 157-162, 2010.

[12] A. A. Basma, A. S. Al-Homoud, and A. Husein, "Laboratory assessment of swelling pressure of expansive soils," Applied Clay Science, vol. 9, no. 5, pp. 355-368, 1995.

[13] E. E. Alonso, J. Vaunat, and A. Gens, "Modeling the mechanical behavior of expansive clays," Engineering Geology, vol. 54, no. 1-2, pp. 173-183, 1999.

[14] R. Bulut, R. L. Lytton, and W. K. Wray, "Soil suction measurement by filter paper," ASCE GSP, vol. 115, 2001.

[15] H. Komine and N. Ogata, "Prediction for swelling characteristics of compacted bentonite," Canadian Geotechnical Journal, vol. 33, no. 1, pp. 11-22, 1996.

[16] D. R. Snethen, An Evaluation of a Methodology for Prediction and Minimization of Detrimental Volume Change of Expansive Soils in Highway Subgrades, Final Report Army Engineer Waterways Experiment Station, Vicksburg, MS, USA, 1979.

[17] D. J. Hamberg, "A simplified method for predicting heave in expansive soils," Doctoral dissertation, Colorado State University, Fort Collins, CO, USA, 1985.

[18] R. Lytton, C. Aubeny, and R. Bulut, Design Procedure for Pavements on Expansive Soils, Texas Transportation Institute, Texas A\&M University System, Austin, TX, USA, 2005.

[19] M. A. El-Sohby and E. A. Rabba, "Some factors affecting swelling of clayey soils," Geotechnical Engineering Journal, SEAGS, vol. 12, pp. 19-39, 1981.

[20] C. Campbell, C. Alton, H. Neil et al., "Comparing in situ soil water characteristic curves to those generated in the lab," in Proceedings of the Second Pan-American Conference on Unsaturated Soils, pp. 18-27, Dallas, TX, USA, 2018.

[21] A. Abeykoon, R. S. Udukumburage, C. Gallage, and T. Uchimura, "Comparison of direct and indirect measured soil-water characteristic curves for silty sand," International Journal of GEOMATE, vol. 13, no. 39, pp. 9-16, 2017.

[22] S. Pandya and A. Sachan, "Matric suction, swelling, and collapsible characteristics of unsaturated expansive soils," Journal of Geotechnical and Transportation Engineering, vol. 4, no. 1, pp. 1-9, 2018.

[23] A. Kandemir, O. Erol, and Y. Erzin, "Swell pressure prediction by suction methods,"vol. 1, pp. 139-142, in Proceedings of the International Conference on Soil Mechanics and Foundation Engineering-International Society for Soil Mechanics and Foundation Engineering, vol. 1, pp. 139-142, AA Balkema, Turkey, 1997.

[24] B. Lin and A. B. Cerato, "The role of micro-scale properties in the study of expansive soils," in Geo-Frontiers 2011: Advances in Geotechnical Engineering, pp. 4129-4136, ASCE Library, Reston, VA, USA, 2011.

[25] A. O. Erol and U. Ergun, "Lateral swell pressures in expansive soils," in Proceedings of the 8th International Conference on Soil Mechanics and Foundations Engineering, pp. 1511-1514, New Delhi, India, 1994.

[26] Y. Erzin and O. Erol, "Swell pressure prediction by suction methods," Engineering Geology, vol. 92, no. 3-4, pp. 133-145, 2007.

[27] B. Zamin, N. Hassan, K. Mehmood, Q. Iqbal, A. Farooq, and M. Tufail, "An experimental study on the geotechnical, mineralogical, and swelling behavior of KPK expansive soils,"
Advances in Civil Engineering, vol. 2021, Article ID 8493091, 13 pages, 2021.

[28] B. Zamin, H. Nasir, K. Mehmood, and Q. Iqbal, "Field-obtained soil-water characteristic curves of KPK expansive soil and their prediction correlations," Advances in Civil Engineering, vol. 2020, Article ID 4039134, 13 pages, 2020.

[29] F. H. Chen, Foundations on Expansive Soils, Elsevier Scientific Publication Company, Amsterdam, Netherlands, 1975.

[30] R. W. Thompson, H. A. Perko, and W. D. Retharnel, "Comparison of constant volume swell pressure and oedometer load-back pressure," in Proceedings of the Fourth International Conference on Unsaturated Soils, Carefree, AZ, USA, April 2006.

[31] S. Singhal, S. L. Houston, and W. N. Houston, "Swell pressure, matric suction, and matric suction equivalent for undisturbed expansive clays," Canadian Geotechnical Journal, vol. 52, no. 3, pp. 356-366, 2015.

[32] T Janardhan, Y. Erzin, and B. H. Rao, "Development of relationships between swelling and suction properties of expansive soils," International Journal of Geotechnical Engineering, vol. 12, no. 1, pp. 53-65, 2018.

[33] A. J. Puppala, T. Manosuthikij, and B. C. S. Chittoori, "Swell and shrinkage strain prediction models for expansive clays," Engineering Geology, vol. 168, pp. 1-8, 2014. 